\title{
EGU21-251
}

https://doi.org/10.5194/egusphere-egu21-251

EGU General Assembly 2021

(c) Author(s) 2021. This work is distributed under

the Creative Commons Attribution 4.0 License.

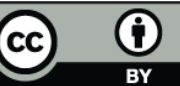

\section{What were the main sources of sediment and associated radiocesium transported during the heavy 2019 typhoons in rivers draining the main Fukushima radioactive plume, Japan?}

Olivier Evrard ${ }^{1}$, Roxanne Durand ${ }^{1}$, Atsushi Nakao ${ }^{2}$, J. Patrick Laceby ${ }^{3}$, Irène Lefèvre ${ }^{1}$, Yoshifumi Wakiyama $^{4}$, Seiji Hayashi ${ }^{5}$, Cécile Asanuma-Brice ${ }^{6}$, and Olivier Cerdan ${ }^{7}$

${ }^{1}$ CNRS-CEA, LSCE - Laboratoire des Sciences du Climat et de l'Environnement, Gif-sur-Yvette, France

(olivier.evrard@Isce.jpsl.fr)

${ }^{2}$ Graduate School of Life and Environmental Sciences, Kyoto Prefectural University, Kyoto, Japan

${ }^{3}$ Alberta Environment and Parks (AEP), Calgary, Alberta, Canada

${ }^{4}$ Institute of Environmental Radioactivity (IER), University of Fukushima, Fukushima, Japan

${ }^{5}$ National Institute for Environmental Science (NIES), Fukushima Branch, Miharu, Japan

${ }^{6}$ Center for Japanese Studies (CRJ-Centre de Recherche sur le Japon) UMR 8173 - EHESS, Paris, France

${ }^{7}$ Bureau de Recherches Géologiques et Minières (BRGM), Département Risques et Prévention, Orléans, France

The Fukushima nuclear accident released large quantities of radionuclides into the environment in March 2011 and generated a 3000-km² plume of soils heavily contaminated with Cs-137. Soil erosion in the region mainly takes place during typhoons generally occurring between July and October (Laceby et al., 2016). During these events, rivers draining the main plume may transport large quantities of sediment and radiocesium. Typhoon Hagibis that occurred in October 2019 was the most intense rainfall event affecting the Fukushima region (rainfall range: 77-558 $\mathrm{mm}$ ) since the nuclear accident in 2011. It led to extensive landsliding and river overflow.

The impact of this event on sediment sources and Cs-137 contamination was quantified through the implementation of sediment fingerprinting using geochemistry and spectrocolorimetry as potential input properties. The signature of potential source material (including cropland prepared for recultivation after decontamination, forests and subsurface material originating from landslides and channel bank collapse; $n=57$ ) was compared with that of sediment deposits collected in the Mano and Niida River catchments late in October 2019. Results show that cropland supplied the main source of sediment (average: 54\%) along with forests (41\%). In contrast, the contribution of subsurface material (5\%) was much lower, likely because landslides and channel bank erosion mainly took place after the flood peak (Evrard et al., 2020). However, this material that deposited at the foot of hillslopes after the typhoon may be mobilized and delivered to the river network by subsequent rainfall events.

Overall, this flood did not modify the decreasing trend observed in terms of Cs-137 contamination in sediment transiting these rivers between 2011 and 2019. Concentrations in Cs-137 observed in sediment collected in 2019 were on average $84-93 \%$ lower than those measured after the accident 
in 2011. These results demonstrate the effectiveness of decontamination conducted on agricultural and residential soils in the region (Evrard et al., 2019), although the role of forests that have not been remediated - as a perennial source of sediment and radiocesium in the region remains to be investigated over the longer term.

References

Evrard, O., Durand, R., Nakao, A., Patrick Laceby, J., Lefèvre, I., Wakiyama, Y., Hayashi, S., AsanumaBrice, C. and Cerdan, O., 2020. Impact of the 2019 typhoons on sediment source contributions and radiocesium concentrations in rivers draining the Fukushima radioactive plume, Japan. Comptes Rendus Géoscience, 352(3): 199-211.

Evrard, O., Laceby, J.P. and Nakao, A., 2019. Effectiveness of landscape decontamination following the Fukushima nuclear accident: a review. SOIL, 5(2): 333-350.

Laceby, J.P., Chartin, C., Evrard, O., Onda, Y., Garcia-Sanchez, L. and Cerdan, O., 2016. Rainfall erosivity in catchments contaminated with fallout from the Fukushima Daiichi nuclear power plant accident. Hydrology and Earth System Sciences, 20(6): 2467-2482. 